\title{
The Role of Analytics in Data-Driven Business Models of Multi-Sided Platforms: An exploration in the food industry
}

\author{
Diane Isabelle, Mika Westerlund, Mohnish Mane and Seppo Leminen
}

\author{
"It's not what you look at that matters, it's what you see." \\ Henry David Thoreau \\ American philosopher
}

\begin{abstract}
The collection and use of data play an increasingly important role in the growth and success of today's digital multi-sided platforms (MSPs). However, many aspiring MSPs lack effective strategies for using data to establish a profitable data-driven business model (DDBM). This study explores how MSPs in the food industry can utilize data to develop such a DDBM. Based on an analysis of seven illustrative cases of high-growth MSPs, namely food delivery and meal kit providers, the study identifies eight factors that reveal the role of analytics in those firms' DDBM, and further classifies them into three DDBM boosters. The findings contribute to our extant knowledge on MSPs and DDBM by addressing how digital platforms in the food industry can leverage big data to optimize their current business processes, predict future value of their product and service offerings, and develop their partnerships.
\end{abstract}

\section{Introduction}

Data-driven business models (DDBMs) are either emergent or new multi-layered, multi-dimensional business models enabled by big data(Hartmann et al., 2016). Several highly diverse industries are moving towards DDBM to survive and compete. Such industries include especially those in which understanding user-buying patterns in an in-depth manner is becoming increasingly important, such as online retailers, the publishing industry, and the financial and insurance service sectors (Brownlow et al., 2015; Zaki et al., 2015). More and more, big data and data analytics play an enabling role in the growth and success of multi-sided platform (MSP) firms, which are digital platforms connecting and serving two or more stakeholders (Evans, 2003; Hagiu, 2006, 2015; Rochet \& Tirole, 2006). The MSP strategy has been fundamental to the emergence of many of today's leading digital businesses from Apple and Google to AirBnB and Uber (Ikeda \& Marshall, 2019).

The analytics, use, and monetization of data are increasingly crucial for the profitability and sustainability of MSPs (Trabucchi et al., 2017). Previous literature shows that apart from revenue growth and cost optimization, data analytics can decrease customer acquisitions costs, retain valuable customers, help predict customer behaviour, improve customer experience, reduce fraud, provide real time offers, and enhance decision making (McAfee \& Brynjolfsson, 2012; Redman, 2015; Wamba et al., 2017). However, data on its own is not a source of competitive advantage since all firms can collect hordes of data from a variety of sources. Rather, data must be purposely analyzed, and activated. Nonetheless, firms face a host of issues - organizational, financial, physical, and human resources - in their attemps to create a competitive capability from the use of data (Gupta \& George, 2016; Ghasemaghaei, 2018), and may easily fail to exploit the benefits of data analytics (Erevelles et al., 2016).

Despite DDBM and data monetization being of high interest to companies (Moro Visconti et al., 2017) and the recent increase of scholarly studies in this domain (Amado et al., 2018; Fiorini et al., 2018), research conducted involving factors that characterize data-based value creation and its role in companies' business 


\section{The Role of Analytics in Data-Driven Business Models of Multi-Sided Platforms: An exploration in the food industry Diane Isabelle, Mika Westerlund, Mohnish Mane and Seppo Leminen}

models are lacking (Lim et al., 2018). In particular, empirical studies on the potential of DDBM innovation in digital platforms to create and appropriate value from big data (Clarke, 2016) and overcome value creation barriers (Lim et al., 2018) are scarce. Given that MSPs constitute an increasingly important business strategy in today's digital economy, there is an urgent need for a better understanding and more comprehensive view of the role of analytics in successful MSP firms' business models.

Our research question for this paper is as follows: How can MSPs successfully establish a new DDBM or strategically shift their current business model to a DDBM through the use of data analytics? To explore this question, we selected the food industry for our investigation, specifically, food delivery and meal kit providers, which is an under-investigated yet growing subcategory of MSPs sharing quite similar business models (Pigatto et al., 2017). At the same time, this highly capital-intensive industry is faced with some challenging issues: customer acquisition costs tend to be very high, while customer retention is generally low, and both supply-chain and logistics are often costly. These challenges can rapidly lead to unprofitable business models even though customer demand for food MSPs is growing. Firms in that industry are generally funded by investors; therefore, it is imperative that their business models generate sustainable results and profits (Ladd, 2018). Hence, this industry represents a particularly fertile area for investigating DDBMs.

Drawing from Lim et al.'s (2018) framework, the objective of this study is to identify essential factors that characterize data-based value creation and its role in DDBM in the food delivery and meal kit industry, through the use of an illustrative case methodology. In so doing, we identify eight key factors that illustrate the role of data analytics in DDBM of successful food MSPs and advance the theoretical concept of "boosters" (Leminen et al., in press), with a study of three boosters that enable successful DDBMs in the food industry. The contributions of the present study to the nascent body of knowledge on DDBMs for digital platforms are as follows. The research, 1) enhances our understanding of how MSPs in the food industry can utilize data analytics to develop a DDBM, 2) fills a gap between big data acquisition and data-based value creation, and 3) provides managers in the food industry with a comprehensive and applicable approach for developing a data-driven model and integrating it with their MSP strategy to successfully achieve a transformation toward a DDBM.

\section{Literature Review and Research Overview}

Big data is defined by five key attributes, commonly referred to as the Five Vs: Volume, Variety, Velocity, Value, and Veracity (McAfee \& Brynjolfsson, 2012; White, 2012; Leventhal, 2013; Fiorini et al., 2018). Value is considered the most important of these attributes (Hmoud et al., 2017). Value can be financial (for example, increased revenue and reduced costs) or intangible (for example, improved customer satisfaction and informed strategic decisions), or a combination of both. While the other four attributes stress data collection, the creation and appropriation of value defines the potential and means for monetization or benefitting from data (Lim et al., 2018). Of note, two recent information technology trends have enabled companies to obtain more value from data: business intelligence and analytics, along with cloud computing (Moro Visconti et al., 2017).

Big data can be classified into three higher level types, namely, structured, semi-structured, and unstructured. Approximately 80 percent of the world's data is unstructured (Balducci \& Marinova, 2018; Sun \& Huo, 2019). Hence, big data often means high volumes of heterogeneous data, which brings unprecedented opportunities to benefit from that data. In fact, previous literature has found that firms using analytics are $36 \%$ more likely to surpass their competitors in revenue growth and operating efficiency (Marshall et al., 2015), and can decrease their customer acquisition costs by $47 \%$ (Wamba et al., 2017).

Redman (2015) identified four types of DDBM: 1) pure content provision, such as Bloomberg corporation; 2) informationalization, which is building data customers need, for example, Waze for route guidance; and 3) infomediation, that is helping people find the data they need, for example Google. The potentially most profitable model looks to become 4) data-driven, by using more and better data to improve strategic and operational decision making, which is the business model of our selected meal kit and food delivery industry.

Engelbrecht and colleagues (2016) argue that innovating business models from a data-driven perspective is crucial to long-term success, while de Oliveira \& Cortimiglia (2017) believe that monetization should 


\section{The Role of Analytics in Data-Driven Business Models of Multi-Sided Platforms: An exploration in the food industry Diane Isabelle, Mika Westerlund, Mohnish Mane and Seppo Leminen}

focus on the scalable parts of the business model. Accordingly, firms can use big data, including usergenerated data, to develop new business models, update and customize existing offerings, and integrate business partners in future business models (Hartmann et al., 2016; Dubé et al., 2018). Without a doubt, the strategic use of data is fast becoming one of the key pillars for successful digital platform business models (Ikeda et al., 2019).

Digital platform businesses have been explored in the network externalities literature (Katz \& Shapiro, 1985). They enable co-creating value among distinct user groups through an intermediary who can internalize network externalities associated with these groups (Evans, 2003; Zott \& Amit, 2010). Hence, conceptualizing a strong value proposition becomes even more complex, as it requires an understanding and management of several needs and objectives across a network of multiple stakeholders to result in creating shared value (Porter \& Kramer, 2011; Baldassarre et al., 2017).

In spite of the growth of data, along with the trends in digital business models and expected benefits from DDBMs, a recent global survey of $\sim 400$ companies showed that $77 \%$ of companies do not have strategies to use big data effectively (Wang et al., 2015). Many companies are thus failing to benefit from integrating big data into their business models (Andersen \& Bjerrum, 2016). The literature offers several reasons for such failures. According to Morabito (2015), big data emphasizes 'utility from' data rather than 'ownership of' data. This means that access to purposeful data is key. Further, raw data is useless unless it is purposely analyzed (Morabito 2015; Gupta \& George, 2016). Jones (2019) notes that there is a difference between data that can be recorded and data that actually gets recorded, as well as between the results from data analyses that get extracted, understood, and exploited for business benefits. Companies also often lack data analysis competencies (Koskinen, 2018).

Vidgen et al. (2017) summarize the top five data strategy issues to overcome: 1) availability of data, 2) using analytics for improved decision making, 3) managing data quality, 4) creating a big data and analytics strategy, and 5) building data skills in the organization. Compounding these issues, business managers must also consider privacy and security concerns, as well as growing regulations (Wong, 2012; Blazquez et al., 2018), and continually develop their business models over time (Muzellec et al., 2015). Not surprisingly, few companies have succeeded in leveraging data and creating a successful DDBM (Mathis \& Köbler, 2016) by linking analytics and big data for value capture (Trabucchi et al., 2017).

More research is needed to provide organizational managers with guidance in these areas (Sorescu, 2017), as evidenced by the gaps in the literature between big data and value creation (Vidgen et al., 2017; Lim et al., 2018). Hence, our objective is to identify key factors that enable multi-sided digital platforms in the meal kit and food delivery industry either to successfully establish or revise their current business model into a DDBM. We draw from Lim and colleagues' (2018) framework for data-based value creation in information-intensive

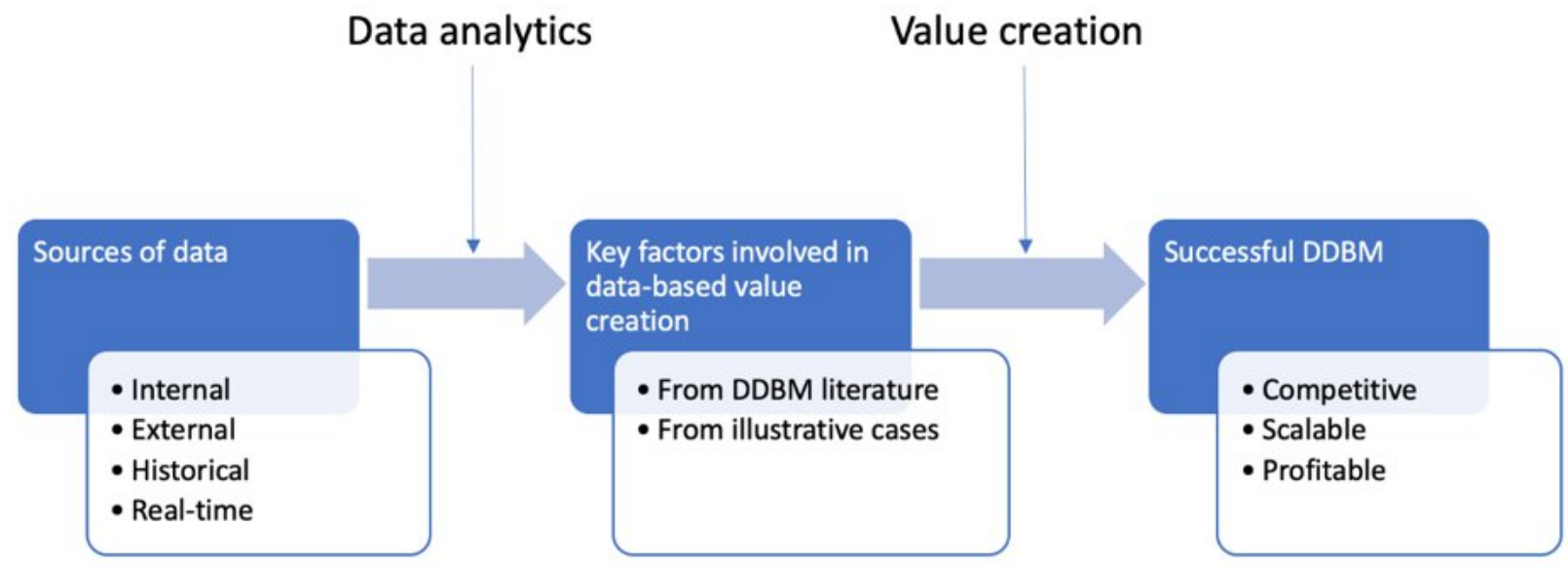

Figure 1. Research overview 


\section{The Role of Analytics in Data-Driven Business Models of Multi-Sided Platforms: An exploration in the food industry Diane Isabelle, Mika Westerlund, Mohnish Mane and Seppo Leminen}

services, and illustrate the context of our research in Figure 1.

\section{Research Design}

Studies on DDBM of MSPs in the food industry context are practically non-existent in spite of several fundamental changes in consumer behaviours (different eating patterns, healthy eating trends, rise of vegan food, preference of ordering in and take-out, etc.), along with novel offerings and business models (online ordering, ready-meal kits delivered to offices and home doors, nutrition-optimized customized meals, etc.). Therefore, learning from existing solutions in an industry, either long established or recently emerged, is an efficient way to contribute to research on business model innovation (Remane et al., 2017).

Applying our research overview approach (Fig. 1), which we drew from Lim and colleagues (2018), we first conducted a literature review of MSPs and DDBMs to identify key factors involed in data-based value creation. Following the example of Leminen and colleagues (2020), we then adopted an illustrative company cases approach by selecting high growth digital platform firms in the meal kit and food delivery industry. We explored their business models and contrasted their key features with these factors found in the previous literature. Our goal was to identify key factors that characterize data-based value creation of successful DDBMs for MSPs in the food industry. This research approach is deemed suitable based on exploratory retrospective intent.

We then proceeded to search for suitable data sources. Data were collected in 2018 in two stages, using an archival research method. In the first stage of data collection, we searched Crunchbase to gather data on MSP firms in the food industry. Initially, 200 companies were found, using MSPs in the food and beverage industry as a high level search criteria. We then further filtered using criteria aligned with the objectives of our research, that is, successful and high growth MSPs providing meal kits and food delivery service that had an established DDBM, and were operating at the time of the study. We applied the following criteria from the literature related to firm survival and high growth: age (over 3 years), customers (over a million), and annual revenue growth rate (over $50 \%$ ). As a result, seven MSPs headquartered in the U.S. and Europe were chosen as illustrative cases. Despite a relatively small sample, our criteria and selection of a specific industry niche allowed us to identify key attributes of successful DDBMs in that industry. Other researchers have used similar approaches given the infancy of the DDBM field (Morris et al., 2013; Trabucchi et al., 2018).

In the second stage of data collection, we individually analyzed the selected seven MSPs through content/archival data analysis to provide accurate accounts of how they achieved successful DDBMs. Data used for this purpose were gathered through various information sources, such as company websites, industry blogs, app stores offering those companies' applications, news media, industry journals, and magazines. News sources included CNBC, Wired, TechCrunch, Business Insider, VentureBeat, and Business Times among others.

We gathered and organized the data on each of the seven cases and conducted content analysis. We were looking for any indications of whether and how these MSP firms had adopted data analytics to support and innovate their DDBMs. We then wrote short case descriptions of each company focusing on how their internal and external data were leveraged in their DDBM and operations. Thereafter, we performed a comparative analysis to find key (dis)similarities across the cases. Table 1 summarizes the seven illustrative cases.

Finally, we contrasted the identified key factors related to the use of data with those identified in the DDBM literature and classified such factors into DDBM boosters enabling successful DDBM of MSPs in the food industry. These factors characterize data-based value creation resulting in competitive, scalable and profitable DDBM in that industry.

\section{Findings and Discussion}

From our analysis, we identified eight key factors involved in the role of analytics and data-based value creation by these successful firms' DDBM. These eight factors were identified and defined through our literature review and an in-depth analyses of various data sources related to our selected MSP cases in the food industry. In particular, we investigated how the MSPs leverage their internal and external data, as well as key performance aspects of their operations. The resulting factors include market trends, real time operations, cross-industry affiliation, optimization of delivery, customer orders, customized recommendations, customer seasonal demands, and 


\section{The Role of Analytics in Data-Driven Business Models of Multi-Sided Platforms: An exploration in the food industry Diane Isabelle, Mika Westerlund, Mohnish Mane and Seppo Leminen}

business results of media plans (see Table 2 for definitions). We further classified these factors into three DDBM boosters: optimization of current services, prediction of future value, and development of partnerships, illustrated in Figure 2.

Table 3 summarizes the results of our analysis by showing which factors appear in each case.

The most widely used data analytics in our cases was for tracking market trends. For instance, Hello Fresh makes data-driven decisions by harnessing Google's keyword planner to analyze trends in searches at specific periods of time. The firm also performs data analyses on dishes that people eat at restaurants. GrubHub uses data to identify upward trends such as meals in bowls and vegan dishes. Deliveroo has established its own business intelligence units in the
Asia Pacific region. Their market trend analyses include exploring food habits and trends, using advanced analytics, data science, and local insights. Further, the company shares its data on customers' preferred dishes to restaurant partners.

Another important factor is real-time operations. Deliveroo analyzes and compares the supply of available delivery drivers with demand based on customer location. Specifically, they use machine learning algorithms to compute the most optimal delivery solution both from the perspective of customers and delivery drivers. Similarly, Good Eggs uses data to deliver groceries to their customers in half the time compared to traditional grocery stores. That said, their real-time operation factor is more about using dynamically changing external data such as weather conditions or traffic data to optimize operations, for example, to

Table 1. Overview of the illustrative cases

\begin{tabular}{|c|c|c|c|c|c|c|}
\hline Company & Business & Headquarters & Funded & Employees & $\begin{array}{l}\text { Funding } \\
\text { received }\end{array}$ & Services \\
\hline $\begin{array}{l}\text { Hello } \\
\text { Fresh }\end{array}$ & Meal kits & $\begin{array}{l}\text { Berlin, } \\
\text { Germany }\end{array}$ & 2011 & $51-100$ & $365 \mathrm{M} \$$ & $\begin{array}{l}\text { Weekly subscription } \\
\text { model. Most popular in } \\
\text { Canada. }\end{array}$ \\
\hline GrubHub & $\begin{array}{l}\text { Online } \\
\text { food } \\
\text { delivery }\end{array}$ & Chicago, US & 2004 & 500-1000 & $284 \mathrm{M} \$$ & $\begin{array}{l}\text { Connects customers with } \\
\text { local restaurants in US \& } \\
\text { UK. Provides delivery for } \\
\text { restaurants. }\end{array}$ \\
\hline Deliveroo & $\begin{array}{l}\text { Online } \\
\text { food } \\
\text { delivery }\end{array}$ & London, UK & 2012 & $101-250$ & $860 \mathrm{M} \$$ & $\begin{array}{l}\text { Europe, Australia and } \\
\text { South Asia. }\end{array}$ \\
\hline Gobble & Meal kits & California, US & 2010 & $11-50$ & $30 \mathrm{M} \$$ & $\begin{array}{l}\text { Meals can be prepared in } \\
15 \text { minutes with one pan. } \\
\text { Customized recipes based } \\
\text { on customer feedback }\end{array}$ \\
\hline $\begin{array}{l}\text { Blue } \\
\text { Apron }\end{array}$ & Meal kits & NY, US & 2012 & $500-1000$ & $119 \mathrm{M} \$$ & $\begin{array}{l}\text { US only. Customized } \\
\text { recipes in recyclable and } \\
\text { sustainable packaging }\end{array}$ \\
\hline Good Eggs & $\begin{array}{l}\text { Organic } \\
\text { grocery } \\
\text { delivery }\end{array}$ & California, US & 2011 & $251-500$ & $65 \mathrm{M} \$$ & $\begin{array}{l}\text { Works with local farmers } \\
\text { and food makers to } \\
\text { deliver groceries in half } \\
\text { the time of traditional } \\
\text { grocery stores }\end{array}$ \\
\hline Chef'd & Meal kits & California, US & 2013 & $101-250$ & $41 \mathrm{M} \$$ & $\begin{array}{l}\text { Charged per meal. } \\
\text { Partnered with famous } \\
\text { world chefs. }\end{array}$ \\
\hline
\end{tabular}




\section{The Role of Analytics in Data-Driven Business Models of Multi-Sided Platforms: An exploration in the food industry Diane Isabelle, Mika Westerlund, Mohnish Mane and Seppo Leminen}

Table 2. Description of identified key factors

\begin{tabular}{|c|c|}
\hline Factor & Description \\
\hline Market trends & $\begin{array}{l}\text { Past and current market behaviors. General tendency or } \\
\text { a course of events over time. Could be short or long time } \\
\text { frames. }\end{array}$ \\
\hline Real time operations & $\begin{array}{l}\text { Series of operations performed on data as it comes in, to } \\
\text { serve real-time applications }\end{array}$ \\
\hline Cross-industry affiliation & $\begin{array}{l}\text { Partnerships between two or more firms that are from } \\
\text { different industries for mutual financial benefit. }\end{array}$ \\
\hline Optimization of delivery & $\begin{array}{l}\text { Provision of the fastest delivery service to customers, by } \\
\text { processing and analyzing data to find the best possible } \\
\text { delivery solution via algorithms incorporating relevant } \\
\text { factors. }\end{array}$ \\
\hline Customers' orders & $\begin{array}{l}\text { Analysis of past data to identify customer preferences, } \\
\text { modify the business model to better suit their needs, and } \\
\text { increase revenue. }\end{array}$ \\
\hline $\begin{array}{l}\text { Customized } \\
\text { recommendations }\end{array}$ & $\begin{array}{l}\text { An understanding of customers' preferences from } \\
\text { current customers, using current and past data to offer } \\
\text { personalized choices. }\end{array}$ \\
\hline $\begin{array}{l}\text { Customer seasonal } \\
\text { demands }\end{array}$ & $\begin{array}{l}\text { An understanding of specific popular food dishes during } \\
\text { specific time periods (e.g., religious, cultural) and } \\
\text { adjusting offerings accordingly. }\end{array}$ \\
\hline $\begin{array}{l}\text { Business results of media } \\
\text { plans }\end{array}$ & $\begin{array}{l}\text { Using algorithms and artificial intelligence to analyze the } \\
\text { outcomes of media plans and feed insights into the } \\
\text { strategic decision-making process. }\end{array}$ \\
\hline
\end{tabular}

anticipate the demand for cold drinks on a sunny day.

An example of cross-industry affiliation is the partnership between Chef'd and Men's Health Magazine for the purpose of sharing customer data and gaining mutual access to each other's customer base. Chef'd has also partnered with famous chefs to plan meals and content that appeal to readers. Likewise, Men's Health Magazine readers can subscribe to Chef'd meal plans to help achieve their fitness goals. Likewise, Chef'd customers looking for a healthy lifestyle are referred to Men's Health Magazine, and receive special discounts for subscription. Thus, customers from one side of the platform benefit from services on the other side.

Optimization of delivery means providing the fastest delivery service to customers. Both internal and external data such as customer orders, number of delivery drivers available, expected time for the meal to be ready, meal packing time, traffic conditions, and navigation maps are processed and analyzed to find the best possible solution to serve customers. Deliveroo uses Frank, a machine learning algorithm capable of calculating thousands of operations per second to provide an optimal delivery solution. This helps them decrease delivery time and thus also helps delivery drivers earn more money in tips.

A factor when stressing historical data is customer orders, which refers to analyzing past customer data accumulated over a period of time. This generally does not involve real-time data and does not focus on customizing offers, but rather on gaining a better understanding of the customer base and their behaviors. Historical data can help reveal insightful correlations that are helpful in modifying the business model. Such data can include correlations between demographics 


\section{The Role of Analytics in Data-Driven Business Models of Multi-Sided Platforms: An exploration in the food industry Diane Isabelle, Mika Westerlund, Mohnish Mane and Seppo Leminen}

Table 3. Comparative business model analysis of illustrative cases

\begin{tabular}{|c|c|c|c|c|c|c|c|}
\hline & $\begin{array}{l}\text { Hello } \\
\text { Fresh }\end{array}$ & GrubHub & Deliveroo & Gobble & Blue Apron & $\begin{array}{l}\text { Good } \\
\text { Eggs }\end{array}$ & Chef'd* \\
\hline Market trends & $\sqrt{ }$ & $\sqrt{ }$ & $\sqrt{ }$ & & & $\sqrt{ }$ & \\
\hline $\begin{array}{l}\text { Real time } \\
\text { operations }\end{array}$ & & & $\sqrt{ }$ & & & $\sqrt{ }$ & \\
\hline $\begin{array}{l}\text { Cross-industry } \\
\text { affiliation }\end{array}$ & & & & & $\sqrt{ }$ & & $\sqrt{ }$ \\
\hline $\begin{array}{l}\text { Delivery } \\
\text { optimization }\end{array}$ & & & $\sqrt{ }$ & & & $\sqrt{ }$ & \\
\hline Customer orders & & $\sqrt{ }$ & $\sqrt{ }$ & $\sqrt{ }$ & & & \\
\hline $\begin{array}{l}\text { Customized } \\
\text { recommendation }\end{array}$ & & & & $\sqrt{ }$ & & & \\
\hline $\begin{array}{l}\text { Customers' } \\
\text { seasonal } \\
\text { demands }\end{array}$ & $\sqrt{ }$ & $\sqrt{ }$ & & & & & \\
\hline $\begin{array}{l}\text { Business results } \\
\text { from media plan }\end{array}$ & & & & & $\sqrt{ }$ & & \\
\hline
\end{tabular}

* has since gone out of business and subsequently acquired by True Food Innovations.

and the type of food that residents in a specific neighbourhood order. For example, GrubHub contrasted past customer orders and weather data and found that their customers preferred mac'n'cheese on a cold day. Results are then used to modify the business model to better suit customers and increase revenue.

Customized recommendations refer to understanding what the existing customer values. Both current and historical data are analyzed to find a customer's favorite recipes and ingredients. For instance, an analysis may show that a customer always likes their sandwich with honey mustard, rather than chili mayonnaise. In this vein, current and new market offerings can be personalized according to customers' preferences, and then suggested for customers to try, as does Gooble, a small MSP firm offering dinner meals that can be prepared in 15 minutes with just one pan.

Data analytics is also used to ensure that the MPS's offerings are aligned with customers' seasonal demands.
This process involves understanding what food dishes are popular during a specific season. Based on analytics, suitable dishes are then created and served to customers during that time period. This means identifying the season's demand through customer data, which can include, for instance, knowledge about customers' traditional celebration needs for certain religious observances or cultural festivals. For example, Hello Fresh uses data analytics along with knowledge of holidays like Thanksgiving Day to prepare turkey and pumpkin-related recipes.

Finally, our cases highlight a factor related to predicting the impact of media plans. Blue Apronis is affiliated with a third-party media company that uses predictive analysis and artificial intelligence to study how well investments in advertising are paying off. Data analytics thus serves to provide the firm with an optimum media mix by providing a forecast of the expected business results of a media plan or ad campaign, helping Blue Apron make informed strategic advertising decisions to achieve cost savings and improve impact. 


\section{The Role of Analytics in Data-Driven Business Models of Multi-Sided Platforms: An exploration in the food industry Diane Isabelle, Mika Westerlund, Mohnish Mane and Seppo Leminen}

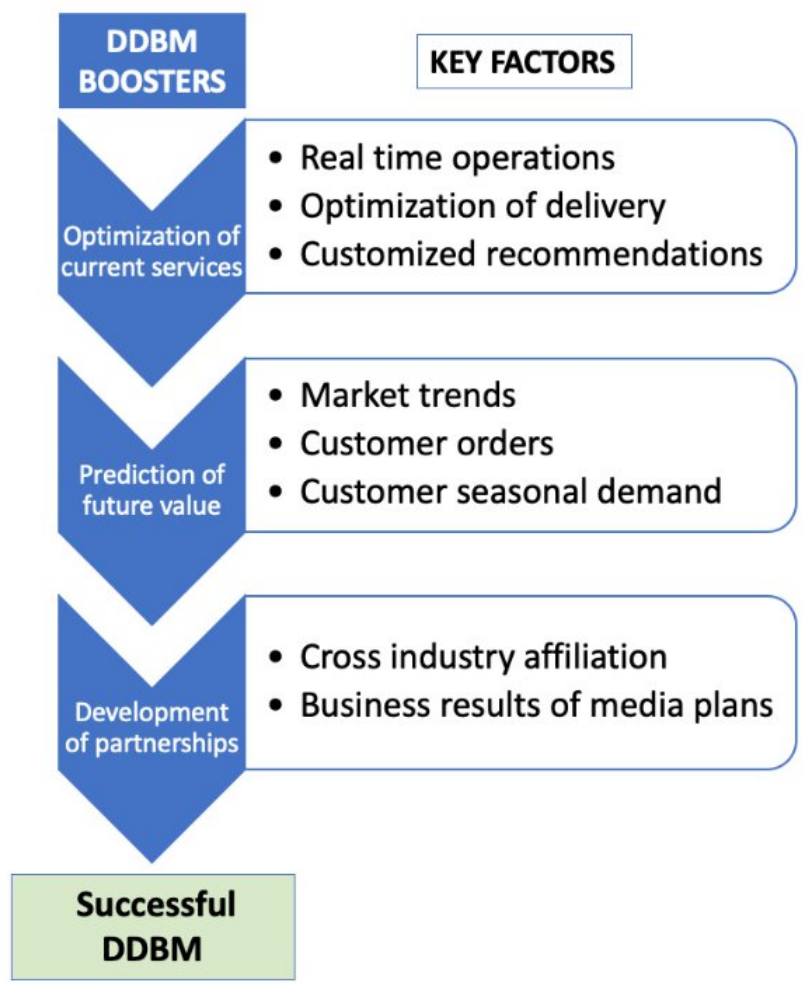

Figure 2. Classification of key factors and DDBM boosters in the food industry

Our findings highlight that Chef'd, which - despite the initial growth and success - went out of business in late 2018 , only used one of our eight factors. It eventually ran out of capital before being able to establish a sustainable and profitable business model in what is now becoming a competitive industry landscape. We can see from Table 3 that none of our selected succesful firms took full advantage of all the recommended factors.

We classified these eight identified factors into three distinct DDBM boosters: 1) optimization of current services, 2) prediction of future value, and 3) development of partnerships. Real time operations, optimization of delivery and customized recommendations. These form the optimization of current services booster. Market trends, customer orders, and customer seasonal demand fall under the prediction of future value booster. Finally, cross industry affiliation and business results of media plans fall under the development of partnerships booster. Figure 2 illustrates the classification of DDBM.

\section{Conclusion}

Our objective in this paper was to understand how digital MSPs in the high-growth food industry, specifically meal kit and food delivery firms, can leverage data analytics to establish or adapt their business model toward a DDBM. In so doing, we aimed to identify key factors that characterize seven successful DDBMs in that industry. In summary, we identified eight factors that reflect the use of data analytics by MSPs in the food industry, then further classified three DDBM boosters: 1) optimization of current services, 2) prediction of future value, and 3) development of partnerships. These boosters highlight that successful DDBMs are ambidextrous because they focus simultaneously on the efficiency of current business and effectiveness of future business, while also increasing the interdependence in company value networks. These findings are parallel to those of Khanagha et al. (2014) who investigated business model renewal during transition to a cloud business model. Companies employing these approaches have been found to be better positioned to increase sales, improve human resource efficiency, provide better customer service, reduce marketing costs, provide optimized delivery service to customers, predict demand in a more accurate manner, improve value 


\section{The Role of Analytics in Data-Driven Business Models of Multi-Sided Platforms: An exploration in the food industry Diane Isabelle, Mika Westerlund, Mohnish Mane and Seppo Leminen}

propositions, and create new offerings and partnerships. Our findings are therefore particularly relevant in the highly competed food industry in which many companies are currently struggling to create profitable DDBMs.

\section{Theoretical contributions}

The results of the study contribute to the current body of knowledge on DDBMs in several ways. First, our findings support the arguments that data analytics, especially machine learning and artificial intelligence-based analytics methods, can be deployed both on internal and external data to achieve cost optimization in online food delivery. This is a key service across most food MSPs and one of the fastest growing areas in the industry (Pigatto et al., 2017). Specifically, analytics can be used to calculate the optimal delivery solution that takes into consideration multiple variables, such as the number of delivery drivers, route traffic, and estimated meal packing time. Second, our results highlight that data analytics plays a key role in the DDBMs of food delivery MSPs in other ways beyond meal delivery. Thus, they suggest that the capability of conducting big data analyses and inclusing analytics as a key element of a company's business model are necessary to create value and gain a competitive advantage (Gupta \& George, 2016). Third, drawing from previous business model design and innovation literature (Khanagha et al., 2014; Zott \& Amit, 2020) our study extended the theoretical concept of "booster", put forth by Leminen et al. (forthcoming), suggesting that DDBM boosters can enable successful data activities in the food industry.

\section{Practical implications}

Our findings provide managers in the food industry with a comprehensive and applicable strategy to develop a data-driven approach that can be integrated with their MSP strategy to successfully achieve transformation toward a DDBM. MSPs operating in the food business should develop their data analytics capabilities and adopt continuous data analysis practices on historical and/or real-time data as a part of their business model, focusing on the eight key factors identified in this study. While internal data are relevant to better understand a company's customers, there is ample external data available that can generate value to MSPs with analytics capabilities. For instance, MSPs can pursue developing their business toward a DDBM by leveraging seasonal demand from data analytics.

Further, environmental and cultural factors such as climate, weather, seasons, festivals, and special occasions, must be diligently considered. Such datadriven decisions will help revenue growth. However, data tends to accumulate, resulting in big data that can be challenging to manage, especially since much of this data is unstructured. Compounding this situation, a key issue is finding skilled labor and developing data analytics capabilities to use business intelligence systems. Collaboration within and across industry sectors can also help in promoting services, while partnering with a media analytics company can assist MSPs in predicting the outcomes of their media advertising costs, using predictive analytics and artificial intelligence.

\section{Limitations and future research areas}

The meal kit and food delivery business area that we selected for investigation is a rapidly growing yet relatively new subsection of the food industry. Therefore, we used an illustrative case approach of successful MSPs for this study. This enabled us to reach a better intra-segment generalization of the results. We further believe that our results and the resulting classification of DDBM boosters are generalizable to other MSP industries.

Future research on MSPs in the food industry could examine a larger sample of companies to gain richer data and insights on analytics practices, as well as validate the link between data analytics and the successes of DDBMs. New entrants have since emerged in that space, which could exemplify additional DDBM factors. Testing the applicabilty of our research approach and performing a case study that could demonstrate the value of our booster concept in business model design and innovation are other potential avenues for investigation. Since studies related to MSP successes and failures are still largely lacking (de Reuver et al., 2018), future research could build from our identified factors, to consider both successes and failures (Stummer et al., 2018), perhaps using a longitudinal research perspective and a business model lifecycle approach (Muzellec et al., 2015). Nonetheless, we believe that the results illuminate that uses of big data in food platform businesses will help MSPs develop more successful DDBMs. 


\section{The Role of Analytics in Data-Driven Business Models of Multi-Sided Platforms: An exploration in the food industry Diane Isabelle, Mika Westerlund, Mohnish Mane and Seppo Leminen}

\section{References}

Amado, A., Cortez, P., Rita, P., \& Moro, S. 2018. Research trends on Big Data in Marketing: A text mining and topic modeling based literature analysis. European Research on Management and Business Economics, 24(1): 1-7. https://doi.org/10.1016/j.iedeen.2017.06.002

Andersen, T.C.K., \& Bjerrum, T.C.B. 2016. Service and data driven multi business model platform in a world of persuasive technologies. Journal of Multi Business Model Innovation and Technology, 4(1): 47-60. https://doi.org/10.13052/jmbmit2245-456X.413

Baldassarre, B., Calabretta, G., Bocken, N.M.P., \& Jaskiewicz, T. 2017. Bridging sustainable business model innovation and user-driven innovation: A process for sustainable value proposition design. Journal of Cleaner Production, 147: 175-186. https://doi.org/10.1016/j.jclepro.2017.01.081

Balducci, B., \& Marinova, D. 2018. Unstructured data in marketing. Journal of the Academy of Marketing Science, 46(4): 557-590.

https://doi.org/10.1007/s11747-018-0581-X

Biglaiser, G. 1993) Middlemen as experts. The RAND journal of Economics, 212-223.

https://www.jstor.org/stable/2555758

Blazquez, D., \& Domenech, J. 2018. Big Data sources and methods for social and economic analyses. Technological Forecasting and Social Change, 130: 99113.

https://doi.org/10.1016/j.techfore.2017.07.027

Brownlow, J., Zaki, M., Neely, A., \& Urmetzer, F. 2015. Data and analytics-data-driven business models: $A$ Blueprint for Innovation. Cambridge Service Alliance.

Clarke, R. 2016. Big data, big risks. Information Systems Journal, 26(1): 77-90.

https://doi.org/10.1111/isj.12088

De Mauro, A., Greco, M., \& Grimaldi, M. 2016. A formal definition of Big Data based on its essential features. Library Review, 65(3): 122-135.

https://doi.org/10.1108/LR-06-2015-0061

de Oliveira, D.T., \& Cortimiglia, M.N. 2017. Value cocreation in web-based multisided platforms: A conceptual framework and implications for business model design. Business Horizons, 60(6): 747-758.

https://doi.org/10.1016/j.bushor.2017.07.002

de Reuver, M., Sørensen, C., \& Basole, R.C. 2018. The digital platform: a research agenda. Journal of Information Technology, 33(2): 124-135.

https://doi.org/10.1057/s41265-016-0033-3

Dubé, L., Du, P., McRae, C., Sharma, N., Jayaraman, S., \& Nie, J.- Y. 2018. Convergent Innovation in Food through Big Data and Artificial Intelligence for Societal-Scale Inclusive Growth. Technology Innovation Management Review, 8(2): 49-65. http://doi.org/10.22215/timreview/1139
Engelbrecht, A., Gerlach, J., \& Widjaja, T. 2016. Understanding the anatomy of data-driven business models-towards an empirical taxonomy. In ECIS, Research Paper 128.

Erevelles, S., Fukawa, N., \& Swayne, L. 2016. Big Data consumer analytics and the transformation of marketing. Journal of Business Research, 69(2): 897904.

https://doi.org/10.1016/j.jbusres.2015.07.001

Evans, D. 2003. The antitrust economics of multi-sided platform markets. Yale Journal on Regulation, 20(2): 325-381.

https://digitalcommons.law.yale.edu/yjreg/vol20/iss $2 / 4$

Fiorini, P. de C., Seles, B.M.R.P., Jabbour, C.J.C., Mariano, E.B., \& Jabbour, A.B.L. de S. 2018. Management theory and big data literature: From a review to a research agenda. International Journal of Information Management, 43: 112-129.

https://doi.org/10.1016/j.ijinfomgt.2018.07.005

Ghasemaghaei, M. 2018. Improving organizational performance through the use of big data. Journal of Computer Information Systems.

https://doi.org/10.1080/08874417.2018.1496805

Gupta, M., \& George, J. F. 2016. Toward the development of a big data analytics capability. Information \& Management, 53(8): 1049-1064. https://doi.org/10.1016/j.im.2016.07.004

Hagiu, A. 2006. Pricing and Commitment by Two-Sided Platforms. Rand Journal of Economics, 37(3): 720-237. https://doi.org/10.1111/j.1756-2171.2006.tb00039.x

Hagiu, A., \& Wright, J. 2015. Multi-sided platforms. International Journal of Industrial Organization, 43: 162-174.

https://doi.org/10.1016/j.ijindorg.2015.03.003

Hartmann, P. M., Zaki, M., Feldmann, N., \& Neely, A. 2016. Capturing value from big data-a taxonomy of data-driven business models used by start-up firms. International Journal of Operations \& Production Management, 36(10): 1382-1406.

https://doi.org/10.1108/IJOPM-02-2014-0098

Hmoud, A.Y., Salim, J., \& Yaakub, M.R. 2017. A twosided market mechanisms toward designing a big data-driven business model for Mobile Network Operators (MNOs). Journal of Telecommunication, Electronic and Computer Engineering (JTEC), 9(2-9): 105-110.

Ikeda, K., \& Marshall, A. 2019. Strategies for competing in markets enabled by digital platforms. Strategy \& Leadership, 47(1): 30-36. https://doi.org/10.1108/SL-10-2018-0097

Jones, M. 2019. What we talk about when we talk about (big) data. Journal of Strategic Information Systems, 28(1): 3-16.

https://doi.org/10.1016/j.jsis.2018.10.005 


\section{The Role of Analytics in Data-Driven Business Models of Multi-Sided Platforms: An exploration in the food industry Diane Isabelle, Mika Westerlund, Mohnish Mane and Seppo Leminen}

Katz, M., \& Shapiro, C. 1985. Network externalities, competition, and compatibility. American Economic Review, 75(3): 424-440.

https://www.jstor.org/stable/1814809

Khanagha, S., Volberda, H., \& Oshri, I. 2014. Business model renewal and ambidexterity: structural alteration and strategy formation process during transition to a Cloud business model. $R \& D$ Management, 44(3): 322-340.

https://doi.org/10.1111/radm.12070

Koskinen, J. 2018. How to Build Competencies for a Data-Driven Business: Keys for Success and Seeds for Failure. Technology Innovation Management Review, 8(10): 18-28.

http://doi.org/10.22215/timreview/1190

Ladd, B. 2018. Demise of Chef'd points to stark choice for meal-kit companies: Get acquired, or die. Forbes. Retrieved from

https://www.forbes.com/sites/brittainladd/2018/07/ 18/the-meal-kit-company-chefd-is-no-more-whatdoes-it-mean-for-the-meal-kitindustry/\#5da565e111bf

Leminen, S., Nyström, A.-G., \& Westerlund, M. (forthcoming). Change processes in open innovation networks - exploring living labs. Industrial Marketing Management.

https://doi.org/10.1016/j.indmarman.2019.01.013

Leminen, S., Rajahonka, M., Wendelin, R., \& Westerlund, M. 2020. Industrial internet of things business models in the machine-to-machine context. Industrial Marketing Management, 84: 298-311. https://doi.org/10.1016/j.indmarman.2019.08.008

Leventhal, R. 2013. Trend: Big data analytics: From volume to value. Healthcare Informatics, 30(2): 12-14.

Lim, C., Kim, K.H., Kim, M.J., Heo, J.Y., Kim, K.J., \& Maglio, P.P. 2018. From data to value: A nine-factor framework for data-based value creation in information-intensive services. International Journal of Information Management, 39: 121-135.

https://doi.org/10.1016/j.ijinfomgt.2017.12.007

Marshall, A., Mueck, S., \& Shockley, R. 2015. How leading organizations use big data and analytics to innovate. Strategy \& Leadership, 43(5): 32-39.

https://doi.org/10.1108/SL-06-2015-0054

Mathis, K., \& Köbler, F. 2016. Data-Need Fit -Towards data-driven business model innovation. Proceedings from the ServDes 2016 - Fifth Service Design and Innovation conference: 458-467.

McAfee, A., \& Brynjolfsson, E. 2012. Big data: The management revolution. Harvard Business Review, 90: 61-69.

Morabito, V. 2015. Big Data and Analytics: Strategic and Organizational Impacts. Berlin: Springer International Publishing.

Moro Visconti, R., Larocca, A., \& Marconi, M. 2017. Big Data-Driven value chains and digital platforms: from Value Co-Creation to Monetization. Available at: SSRN 2903799.
Morris, M.H., Shirokova, G., \& Shatalov, A. 2013. The business model and firm performance: The case of Russian food service ventures. Journal of Small Business Management, 51(1): 46-65.

https://doi.org/10.1111/j.1540-627X.2012.00377.x

Muzellec, L., Ronteau, S., \& Lambkina, M. 2015. Twosided Internet platforms: A business model lifecycle perspective. Industrial Marketing Management, 45: 139-150.

https://doi.org/10.1016/j.indmarman.2015.02.012

Pigatto, G., Machado, J.G.D.C.F., Negreti, A.D.S. \& Machado, L.M. 2017. Have you chosen your request? Analysis of online food delivery companies in Brazil. British Food Journal, 119(3): 639-657. https://doi.org/10.1108/BFJ-05-2016-0207

Porter, M.E. \& Kramer, M.R. 2011. The big idea: Creating shared value. Harvard Business Review, 89(1), 2.

Redman, T.C. 2015. 4 Business models for the data age. Harvard Business Review, 93(5).

Remane, G., Hanelt, A., Tesch, J.F., \& Kolbe, L.M. 2017. The business model pattern database - A tool for systematic business model innovation. International Journal of Innovation Management, 21(1): 1750004. https://doi.org/10.1007/978-3-319-98723-1_5

Rochet, J.C., \& Tirole, J. 2006. Two-sided markets: A progress report. RAND Journal of Economics, 37(3): 645-667.

https://www.jstor.org/stable/25046265

Sorescu, A. 2017. Data driven business model innovation. Journal of Product Innovation Management, 34(5): 691-696.

https://doi.org/10.1111/jpim.12398

Sun, Z., \& Huo, Y. 2019. The Spectrum of Big Data Analytics. Journal of Computer Information Systems. https://doi.org/10.1080/08874417.2019.1571456

Stummer, C., Kundisch, D., \& Decker, R. 2018. Platform launch strategies. Business \& Information Systems Engineering, 60(2): 167-173.

https://doi.org/10.1007/s12599-018-0520-x

Trabucchi, D., Buganza, T., \& Pellizzoni, E. 2017. Give Away Your Digital Services. Research-Technology Management, 60(2): 43-52.

https://doi.org/10.1080/08956308.2017.1276390

Vidgen, R., Shaw, S., \& Grant, D.B. 2017. Management challenges in creating value from business analytics. European Journal of Operational Research, 261(2): 626-639.

https://doi.org/10.1016/j.ejor.2017.02.023

Wamba, S.F., Gunasekaran, A., Akter, S., Ren, S.J.F., Dubey, R. \& Childe, S.J. 2017. Big data analytics and firm performance: Effects of dynamic capabilities. Journal of Business Research, 70: 356-365. https://doi.org/10.1016/j.jbusres.2016.08.009

Wang, Y., Kung, L., Ting, C., \& Byrd, T. A. 2015. Beyond a technical perspective: understanding big data capabilities in health care. In System sciences (HICSS), 48th Hawaii international conference: 3044-3053. 


\section{The Role of Analytics in Data-Driven Business Models of Multi-Sided Platforms: An exploration in the food industry Diane Isabelle, Mika Westerlund, Mohnish Mane and Seppo Leminen}

White, M. 2012. Digital workplaces: Vision and reality. Business Information Review, 29: 205-214. https://doi.org/10.1177/0266382112470412

Wong, R. 2012. Big data privacy. Journal of Information Technology Software Engineering, 2(5): 114.

Zaki, M., Lillegraven, T., \& Neely, A. 2015. Moving Towards a Data-Driven Business Model (DDBM) in the Online Newspaper Publishing Industry. University of Cambridge.

Zott, C., \& Amit, R. 2010. Business model design: an activity system perspective. Long range planning, 43(2-3): 216-226.

https://doi.org/10.1016/j.lrp.2009.07.004

\section{About the Authors}

Diane Isabelle is an Associate Professor of International Business. Her research focuses broadly on the areas of science, innovation and techno-entrepreneurship within a global context. Specifically, her research is organized around the following three inter-related themes: 1) International entrepreneurship \& ecosystems, 2) Internationalization (International New Ventures and SMEs), 3) Global collaborative research and Science, Technology and Innovation policy. In addition to these themes, she is researching and publishing on Technology-integrated and international interdisciplinary experiential learning in higher education. Prior to joining Sprott in 2011, Dr. Isabelle worked in several senior executive roles related to science, technology and industrial research (Industrial Research Assistance Program IRAP) at the National Research Council of Canada (NRC), the Government of Canada's premier research and technology organization. She started her career as a project engineer for several multinational firms, including General Electric, Esso and Boeing Aerospace.

Mika Westerlund, DSc (Econ), is an Associate Professor at Carleton University in Ottawa, Canada. He previously held positions as a Postdoctoral Scholar in the Haas School of Business at the University of California Berkeley and in the School of Economics at Aalto University in Helsinki, Finland. Mika earned his doctoral degree in Marketing from the Helsinki School of Economics in Finland. His research interests include open and user innovation, the Internet of Things, business strategy, and management models in high-tech and service-intensive industries.

Mohnish Mane, MEng, is a Senior Business Analyst at NTT Data Canada. Previously, he held a similar position at Tata Consultancy services. Mohnish earned his Master's degree in Technology Innovation Management at Carleton University, focussing on data driven business models. $\mathrm{He}$ is a solutions-driven business analyst with diverse experience in Power, Healthcare and Oil and Gas industries where he has lead cross functional teams in the development, documentation and delivery of complex IT projects. In his free time, he is involved in conducting various cooperate social responsibility events and volunteering opportunities.

Seppo Leminen is a Full Professor of Innovation and Entrepreneurship in the USN School of Business at the University of South-Eastern Norway in Norway, a Research Director at Pellervo Economic Research in Finland, an Adjunct Professor of Business Development at Aalto University in Finland and an Adjunct Research Professor at Carleton University in Canada. He holds a doctoral degree in Marketing from the Hanken School of Economics and a doctoral degree in Industrial Engineering and Management in the School of Science at Aalto University. His research and consulting interests include living labs, open innovation, innovation ecosystems, robotics, the Internet of Things (IoT), as well as management models in high-tech and service-intensive industries. Results from his research have been reported in Industrial Marketing Management, the Journal of Cleaner Production, the Journal of Engineering and Technology Management, the Journal of Business \& Industrial Marketing, Management Decision, the International Journal of Innovation Management, and the Technology Innovation Management Review, among many others.

Citation: Isabelle, D., Westerlund, M., Leminen, S. 2020. The Role of Analytics in Data-Driven Business Models of Multi-Sided Platforms: An exploration in the food industry. Technology Innovation

Management Review, 10(7): 4-15.

http://doi.org/10.22215/timreview/1371

\section{(cc) BY}

Keywords: Digital platforms, data analytics, data-driven business models DDBM boosters, food industry 